\title{
cmaJOPEN
}

\section{SARS-CoV-2 transmission in kindergarten to grade 12 schools in the Vancouver Coastal Health region: a descriptive epidemiologic study}

\author{
Diana Bark MD MPH, Nalin Dhillon MSc, Martin St-Jean MSc, Brooke Kinniburgh MPH, \\ Geoff McKee MD MPH, Alexandra Choi MD MHSc
}

\section{Abstract}

Background: There is an urgent need to assess the role of schools in the spread of SARS-CoV-2 in Canada to inform public health measures. We describe the epidemiology of SARS-CoV-2 infection among students and staff in the Vancouver Coastal Health (VCH) region in the first 3 months of the 2020/2021 academic year, and examine the extent of transmission in schools.

Methods: This descriptive epidemiologic study using contact tracing data included individuals aged 5 years and older with SARS-CoV-2 infection, reported between Sept. 10 and Dec. 18, 2020, who worked in or attended kindergarten to grade 12 $(\mathrm{K}-12)$ schools in person in the $\mathrm{VCH}$ region. We described case and cluster characteristics and reported the number of schoolbased transmissions.

Results: During the study period, 699 cases of SARS-CoV-2 infection were reported (55 cases per $10000 \mathrm{VCH}$ school population). Among cases in VCH resident staff and students, 52.5\% (354/674) were linked to a household case or cluster; less than $1.5 \%(<10)$ of infected individuals were hospitalized and none died. Out of 699 cases present at school, 26 clusters with schoolbased transmission resulted in 55 secondary cases. Staff members accounted for $53.8 \%$ of index cases (14/26) while making up $14.3 \%$ of the school population (17 742/123 647). Among clusters, 88.5\% (23) had fewer than 4 secondary cases.

Interpretation: In our population during the study period, there were no deaths and severe disease was rare; furthermore, schoolbased SARS-CoV-2 transmissions were uncommon and clusters were small. Our results, which relate primarily to symptomatic disease, support the growing body of evidence that schools likely did not play a major role in SARS-CoV-2 spread in 2020.

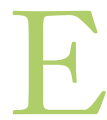
arly in the pandemic, schools closed across Canada to help reduce the circulation of SARS-CoV-2 and decrease risks associated with infection among staff and students. ${ }^{1}$ Evidence has since suggested that school closures and decreased in-person learning have had negative impacts on the mental health, well-being, educational attainment, social connection, health care access and health behaviours of students, families and staff. ${ }^{1-12}$ Combined with high socioeconomic tolls, ${ }^{13-15}$ these unintended consequences have compelled consideration of the efficacy of school closures in limiting morbidity and mortality associated with the COVID-19 pandemic.

Evidence now indicates that age is a risk factor for severe disease and children typically experience a mild course of illness. ${ }^{16-22}$ There is also a growing body of literature suggesting that children's in-person school attendance may not be an important driver of transmission; contact-tracing and test-based studies from other jurisdictions have identified little or no transmission in the school setting. ${ }^{23-34}$ Internation- ally, studies illustrate that school reopening has not affected numbers of pediatric cases s $^{23,35,36}$ and that the risk of SARSCoV-2 infection has not increased for educational staff working with children. ${ }^{30,36,37}$

There are limited peer-reviewed data in Canada regarding risk of SARS-CoV-2 transmission in schools, although Ottawa Public Health has reported low rates of school-based transmission. ${ }^{38}$ Given that transmission risk is influenced by community-level epidemiology, public health measures, health system infrastructure and other jurisdictional factors, this study contributes needed evidence within the Canadian

\section{Competing interests: None declared.}

This article has been peer reviewed.

Correspondence to: Alexandra Choi, alexandra.choi1@vch.ca CMAJ Open 2021 August 24. DOI:10.9778/cmajo.20210106 
context. We aimed to describe cases of SARS-CoV-2 infection among students and staff in the Vancouver Coastal Health (VCH) region who attended kindergarten to grade 12 $(\mathrm{K}-12)$ schools in person, assess the extent of SARS-CoV-2 transmission in schools and characterize clusters where school-based transmission was observed.

\section{Methods}

\section{Study design and setting}

This descriptive epidemiologic study using contact-tracing data was population-based and retrospective. We described the incidence and characteristics of cases of SARS-CoV-2 infection reported among $\mathrm{K}-12$ staff and students in the Vancouver Coastal Health (VCH) region. The study period was from Sept. 10, 2020, to Dec. 18, 2020. Vancouver Coastal Health serves more than 1.2 million people ${ }^{39}$ across urban, rural and remote geographies.

During the study period, although mass gatherings remained prohibited in British Columbia, schools and businesses were open with safety plans in place, and masks were encouraged but not required. Travel and gatherings in private residences were restricted gradually, starting in November 2020. There were no stay-at-home requirements. ${ }^{40}$ Symptomatic testing was widely available, and contact tracing was conducted for all positive cases. ${ }^{41}$

Schools in BC reopened after summer holidays on Sept. 10, 2020, and closed for winter break after Dec. 18, 2020. Before reopening, schools implemented COVID-19 safety plans developed with support from public health officials across health authorities, which included public health measures (e.g., testing and contact-tracing protocols), environmental measures (e.g., enhanced cleaning and disinfection), administrative measures (e.g., scheduling and work practices, health and wellness policies, and cohorting), personal measures (e.g., staying home when sick, physical distancing, hand hygiene and respiratory etiquette) and personal protective equipment. Use of nonmedical masks was supported, but not always required (Appendix 1, available at www.cmajopen.ca/content/9/3/E810/suppl/DC1). ${ }^{42}$

\section{Cases}

We extracted all laboratory-confirmed, probable-laboratory and probable-epidemiologically linked cases among individuals aged 5 years and older at the time of the case report between Sept. 10 and Dec. 18, 2020, who reported working in or attending a $\mathrm{K}-12$ school within the $\mathrm{VCH}$ region during their incubation or infectious periods. We excluded cases of individuals who exclusively worked in or attended a daycare or postsecondary institution, attended school online or were home-schooled. School staff and student cases were categorized as either school-aged (age 5-17 yr) or aged 18 years and older.

Potential school-transmission events were defined as situations in which a case of SARS-CoV-2 infection was epidemiologically linked to another case at school, and transmission likely occurred in the school setting, whether in the course of classroom or nonclassroom activities. ${ }^{27,31,33}$ To identify potential school-transmission events, we analyzed all clusters in which 2 or more cases were reported within a 14-day period in a school. Cases of individuals who did not interact with staff or students in the learning setting (e.g., building maintenance staff only present after school hours) were excluded from the cluster analysis.

\section{Public health investigation and response}

Nucleic acid amplification testing for SARS-CoV-2 was available for anyone with symptoms, and was advised for students or staff with fever or new symptoms persisting longer than 24 hours. Tests were generally processed within 24 hours. Positive tests were automatically reported to VCH's Office of the Chief Medical Health Officer, which investigated cases within 24 hours and identified contacts. ${ }^{43}$

Contact tracing was conducted by health sciences professionals using a standardized electronic form adapted from the provincial COVID-19 case report form ${ }^{44}$ via telephone interviews with the infected individuals or their proxies to obtain information including demographic characteristics, comorbidities, symptoms, school attendance or work details, activities during incubation and infectious periods, contacts with known confirmed or probable cases of SARS-CoV-2 infection, and exposures to clusters or outbreaks of SARS$\mathrm{CoV}-2$ infection.

Medical health officers performed qualitative individual risk assessments for each contact via a review of the contacttracing data, integrating each infected individual's symptoms, ages of individuals and contacts, nature and duration of contact, setting (e.g., indoor or outdoor), and presence or absence of known SARS-CoV-2 transmission. Factors constituting high-risk exposures included direct contact with infectious body fluids (e.g., via sharing vapes or being coughed or sneezed on) and prolonged (>15 min) contact with an individual with symptomatic infection, face to face or at close range; ${ }^{43}$ thus, close contacts were identified among classmates. Factors constituting low-risk exposures included the absence of interactions or interactions outdoors of limited duration and at a distance (i.e., $>2 \mathrm{~m}$ ). ${ }^{43}$

Individuals with high-risk exposures were advised to selfisolate for 14 days and were monitored for emergence of symptoms during their incubation periods. Symptomatic individuals were directed to seek testing and few declined. Those with lower-risk exposures were advised to selfmonitor for symptoms and present for testing accordingly. Asymptomatic individuals were tested at the discretion of the medical health officer.

\section{Data sources and extraction}

Vancouver Coastal Health's electronic COVID-19 case and contact tool is a custom, noncertified electronic medical record (EMR) built to EMR standards. It records first-hand information collected as a part of contact tracing, and is designed to capture relationships between cases, contacts, exposures, clusters and outbreaks. The public health team flags epidemiologic linkages between cases determined 
through contact tracing on the EMR through a software feature. Staff members who chart in the EMR receive training and use standardized tools, including interview scripts and workflow guidance. Information such as age, sex and laboratory data are triangulated based on unique identifiers through integration with the provincial electronic health record platform, CareConnect. Data quality is assured through routine diagnostics and complaint-driven investigations.

Data used in the study were downloaded from the EMR in Excel format by M.S.-J. N.D. cleaned and verified the data; duplicate case entries were discarded based on unique identifiers, and cases with missing or incorrect Health Service Delivery Area fields were reclassified based on cities of residence or postal codes. For the temporally associated cases, D.B. verified school attendance or work status by chart review and excluded cases according to the selection criteria.

N.D. extracted the demographic characteristics, school name, grade, role (staff or student), attendance dates, comorbidities, symptoms and epidemiologic linkages to other cases within and outside of school, and the research team checked the data for accuracy. Hospitalizations and intensive care unit (ICU) admissions to VCH hospitals were determined using individual data linkages to acute care data. The Provincial Health Services Authority individually matched and provided hospitalization data for $\mathrm{VCH}$ staff and student cases hospitalized at BC Children's Hospital. Districts confirmed denominators of staff and students attending in person during the study period.

Data extraction for the cluster analysis was conducted by D.B. using a structured data abstraction tool and data dictionary (Appendix 2, Table A1, available at www.cmaj open.ca/content/9/3/E810/suppl/DC1). Cases' likely sources of infection were categorized as household, social, school or other. A case was determined to be a contact's likely source of viral acquisition if they had prolonged contact during the case's infectious period and the contact's incubation period. ${ }^{43}$ If there was no contact with a positive case, this was recorded. All cases with multiple potential sources of acquisition were reviewed by D.B. and A.C., with high (93\%) interrater reliability. The source of acquisition was attributed to the school if the nonschool source had an unclear symptom-onset date and no clear source of acquisition themselves. Index and secondary cases were categorized by symptom-onset date, and secondary cases' close contacts who became laboratory-confirmed or probable cases were categorized as tertiary cases.

\section{Statistical analysis}

All analyses were conducted via statistical computing software RStudio. We based $p$ values on Pearson $\chi^{2}$ and independent $t$ tests for categorical and continuous variables, respectively.

\section{Ethics approval}

In consultation with the University of British Columbia Office of Research Ethics, this study did not require institutional research ethics review as it was completed as part of routine public health surveillance and operations.

\section{Results}

During the study period, 17742 staff and 105905 students worked in or attended school in person at a total of 358 schools (104 independent and 254 public) in the $\mathrm{VCH}$ region. In the same period, 699 cases of SARS-CoV-2 infection were reported among staff and students (Figure 1) in 270 unique VCH-region $\mathrm{K}-12$ schools, representing an incidence of 55 cases per 10000 population. During the study period, the weekly incidence peaked the week of Nov. 15-21, 10 weeks after school reopening (Figure 2; Appendix 2, Figures A1 and A2).

Of the 699 individuals with reported SARS-CoV-2 infection, 674 (96.4\%) resided in the $\mathrm{VCH}$ region; these cases are described in Table 1 . Notably, adults ( $\geq 18 \mathrm{yr}$ ) more frequently reported comorbidities and were less frequently linked to a confirmed case or cluster compared with children $(5-17 \mathrm{yr})$ ( $p$ values < 0.01). The $25(3.6 \%)$ staff and students with SARS-CoV-2 infection who resided outside the VCH region, while excluded from Table 1 , were included in the cluster analysis.

\section{Clusters of SARS-CoV-2 infection in schools}

A total of 71 school clusters occurred, totalling 251 cases during the study period (Figure 3 ). No school-based transmission was suspected in 45 clusters (63.3\%), with all 142 cases within these clusters likely acquiring SARS-CoV-2 infection outside of school. Within the 26 clusters containing at least 1 schoolacquired case, a further 28 cases likely acquired infection outside of school. Of the 170 cases (19 staff and 151 students) temporally clustered but without evidence of school-based

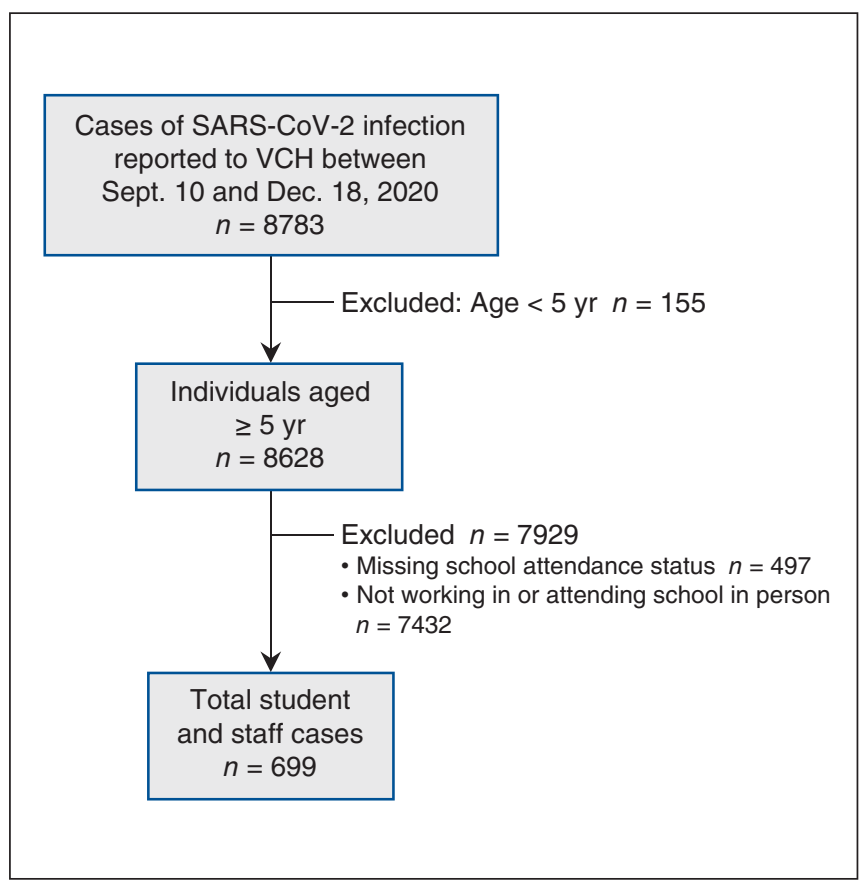

Figure 1: Flow diagram showing study population selection (including staff and students not residing in the Vancouver Coastal Health $[\mathrm{VCH}]$ region). 


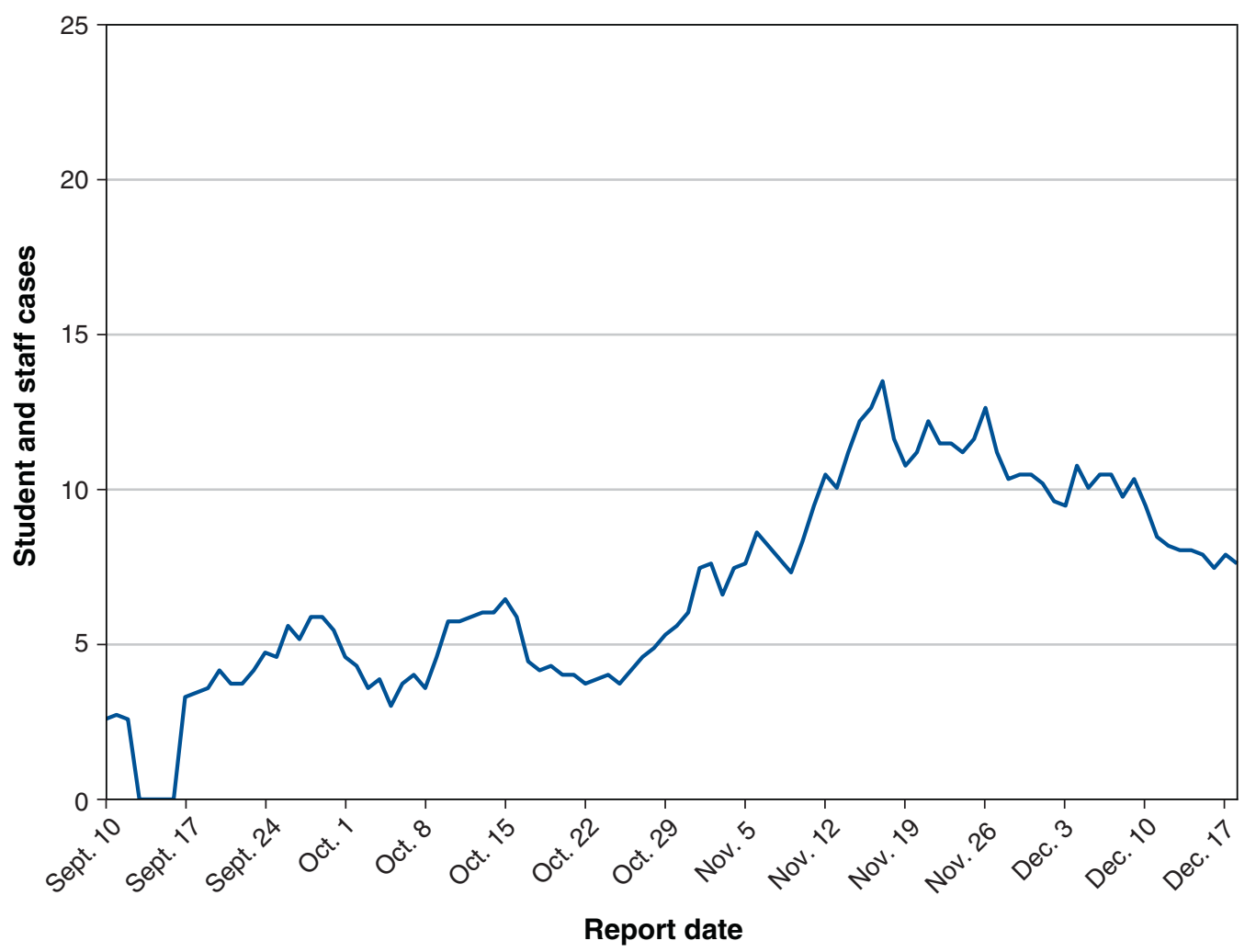

Figure 2: Seven-day average of new cases of SARS-CoV-2 infection among staff and students attending kindergarten to grade 12 schools in the Vancouver Coastal Health region reported during the study period (Sept. 10 to Dec. 18, 2020).

transmission, 107 (62.9\%) were attributable to household contacts, $17(10.0 \%)$ to social networks, $4(2.4 \%)$ to sports teams and $2(1.2 \%)$ to work outside of school. Forty students and staff $(23.5 \%)$ had no known contact with another case inside or outside of school. There were no school closures because of SARS-CoV-2 transmission during the study period.

\section{Cases with evidence of school-based transmission}

Out of 699 cases present at school, likely transmission stemming from $26(3.7 \%)$ index cases resulted in 55 secondary cases at school. A total of 237 close contacts were identified from these 55 secondary cases, and 10 became tertiary cases. Staff accounted for $53.8 \%$ of index cases (14/26) and $25.5 \%$ of secondary cases $(14 / 55)$. Staff cases $(n=28)$ included 19 teachers, 6 support workers, and 3 principals or office staff members. Of the 81 index and secondary cases, 47 (58.0\%) worked in or attended a K-7 school, 25 (30.9\%) a grade 8-12 school and $9(11.1 \%)$ a $\mathrm{K}-12$ school. The ratio of secondary cases to total primary cases was 0.09 .

The characteristics of clusters with school-based transmission are presented in Table 2. Among 26 total clusters, 13 $(50.0 \%)$ had 1 secondary case, $10(38.5 \%)$ had $2-3$ secondary cases and $3(11.5 \%)$ had 4 or more secondary cases. All clusters with 4 or more secondary cases had an index staff case and occurred in grades $\mathrm{K}-7$. The median size of clusters was 3 (range 2-8) when the index case was a staff member compared with 2 (range 2-3) when the index case was a student. There were $8(30.8 \%)$ clusters involving students only, all among grades $4-12$, and 4 clusters (15.4\%) involving staff members only. Of the 14 clusters including both staff and students, 9 $(64.3 \%)$ occurred in grades $\mathrm{K}-7$ and 5 (35.7\%) in grades 8-12.

School-based activities where transmission may have occurred are presented in Table 3. Evidence of transmission was most commonly found in a shared classroom, but no specific class type was more frequently identified. For some cases, there were multiple exposures settings within the school, notably through socializing with a classmate.

\section{Interpretation}

During the study period, the number of cases of SARS$\mathrm{CoV}-2$ infection reported among $\mathrm{K}-12$ students and staff in the $\mathrm{VCH}$ region gradually increased in the context of broader societal reopening, reaching a peak incidence 10 weeks (about 5 incubation periods) after school reopening and declining thereafter in the context of increasingly restrictive public 


\begin{tabular}{|c|c|c|c|}
\hline \multirow[b]{2}{*}{ Characteristic } & \multicolumn{3}{|c|}{ No. (\%) of casest } \\
\hline & $\begin{array}{c}\text { Adults ( } \geq 18 \mathrm{yr} \text { ) } \\
\quad n=157\end{array}$ & $\begin{array}{c}\text { Children } \\
\text { (5-17 yr) } \\
n=517\end{array}$ & $\begin{array}{c}\text { Total } \\
n=674\end{array}$ \\
\hline $\begin{array}{l}\text { Age at time of report, yr, median } \\
\text { (range) }\end{array}$ & $39(18-73)$ & $12(5-17)$ & $14(5-73)$ \\
\hline Age $\geq 65 \mathrm{yr}$ at time of report & $2(1.3)$ & NA & $2(0.3)$ \\
\hline \multicolumn{4}{|l|}{ Sex } \\
\hline Female & $104(66.2)$ & $224(43.3)$ & $328(48.7)$ \\
\hline Male & $53(33.8)$ & 292 56.5) & $345(51.2)$ \\
\hline \multicolumn{4}{|l|}{ Health service delivery area } \\
\hline Coastal rural & $6(3.8)$ & $33(6.4)$ & $39(5.8)$ \\
\hline Coastal urban & $29(18.5)$ & $107(20.7)$ & $136(20.2)$ \\
\hline Richmond & $29(18.5)$ & 99 (19.1) & $128(19.0)$ \\
\hline Vancouver & $93(59.2)$ & $278(53.8)$ & $371(55.0)$ \\
\hline \multicolumn{4}{|l|}{ Linked to confirmed case or cluster } \\
\hline No & 62 (39.5) & $114(22.1)$ & $176(26.1)$ \\
\hline Yes, non-household contact & 50 (31.8) & 94 (18.2) & $144(21.4)$ \\
\hline Yes, household contact & $45(28.7)$ & $309(59.8)$ & $354(52.5)$ \\
\hline \multicolumn{4}{|l|}{ Case status } \\
\hline $\begin{array}{l}\text { Recovered and removed from } \\
\text { isolation }\end{array}$ & $157(100)$ & $517(100)$ & $674(100)$ \\
\hline Deceased & $0(0)$ & $0(0)$ & $0(0)$ \\
\hline Ever hospitalized & - & - & $<10(<1.5)$ \\
\hline Ever admitted to ICU & - & - & $<10(<1.5)$ \\
\hline One or more comorbidity & $36(22.9)$ & $37(7.2)$ & $73(10.8)$ \\
\hline \multicolumn{4}{|l|}{ Comorbidity type $\neq$} \\
\hline Cancer & $2(1.3)$ & $0(0)$ & $2(0.3)$ \\
\hline Cardiac & $5(3.2)$ & $1(0.2)$ & $6(0.9)$ \\
\hline Diabetes & $7(4.5)$ & $3(0.6)$ & $10(1.5)$ \\
\hline Immunocompromised & $3(1.9)$ & $8(1.5)$ & $11(1.6)$ \\
\hline Pregnant & $3(1.9)$ & $0(0)$ & $3(0.4)$ \\
\hline Respiratory & $2(1.3)$ & $6(1.2)$ & $0(0)$ \\
\hline Smoking or vaping & $27(17.2)$ & $22(4.3)$ & $49(7.3)$ \\
\hline One or more COVID-19 symptoms & $155(98.7)$ & $501(96.9)$ & $656(97.3)$ \\
\hline \multicolumn{4}{|c|}{$\begin{array}{l}\text { Note: ICU = intensive care unit, } \mathrm{NA}=\text { not applicable, } \mathrm{VCH}=\text { Vancouver Coastal Health. } \\
\text { "Data accurate as of Jan. } 12,2021 \text {. Excludes } 25 \text { cases who resided outside of the } \mathrm{VCH} \text { region but worked in or } \\
\text { attended school in person in the } \mathrm{VCH} \text { region. Although VCH followed up on all school cases, clusters and exposures } \\
\text { at schools within the VCH region, long-term follow-up of individual cases is typically completed in the health authority } \\
\text { in which the individual resides. Therefore, complete information from long-term follow-up (e.g., hospitalization data) } \\
\text { was available only for individuals residing within the VCH region. } \\
\text { †Unless stated otherwise. } \\
\text { fComorbidity types were not mutually exclusive. }\end{array}$} \\
\hline
\end{tabular}

health measures. The trend in new cases among the school population mirrored that of the general population in the VCH region. ${ }^{45}$ Hospitalizations and ICU admissions were rare, and there were no deaths.
Although as many as 251 cases were temporally clustered with another case in the same school within a 14-day period, $170(68 \%)$ of these cases had no evidence of school-based transmission. When school-based transmissions occurred, the 


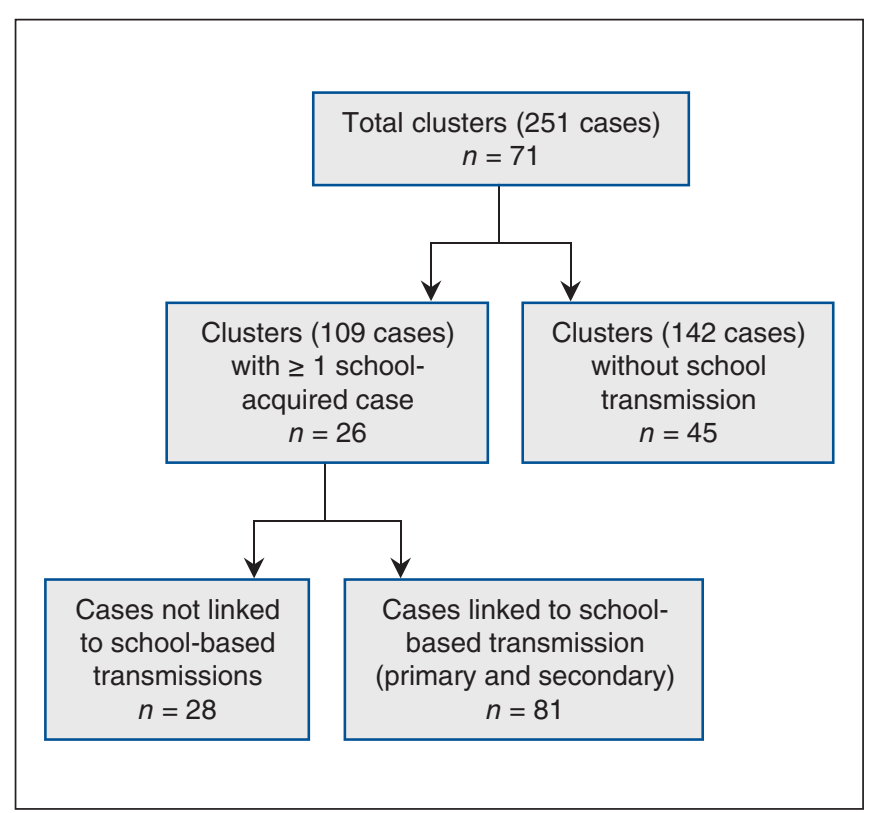

Figure 3: Flow diagram showing characteristics of school cluster transmission.

number of identified secondary cases was small; a total of 55 school-acquired cases represented $0.04 \%$ of individuals working in or attending a $\mathrm{K}-12$ school in the $\mathrm{VCH}$ region. Staff members were disproportionately identified as the index cases compared with their makeup of the school population. A shared classroom accounted for most transmissions; no particular class or activity was noticeably higher risk.

Our findings support the growing body of evidence that schools are likely not an important driver of SARS-CoV-2 spread. ${ }^{23,35,36}$ In concordance with other studies, we found that a household case was the most common source of infection for school-aged children ${ }^{30,32}$ and that school-based acquisitions were uncommon. ${ }^{29,30,32,33}$ Individuals with SARS-CoV-2 infection seldom infected others at school; out of 699 student and staff cases, we identified likely schoolbased transmissions stemming from 26 index cases (3.7\%). The ratio of secondary cases to total primary cases was 0.09 in the school setting, compared with 0.27 observed in Luxembourg, ${ }^{30} 0.08$ in Germany ${ }^{32}$ and 0.02 in South Korea. ${ }^{23}$ Although we did not systematically track the number of school contacts per index case, the secondary attack rate is likely to be very low given the low number of identified secondary cases, in concordance with prior studies across several countries..$^{24,25,28,30}$ As observed elsewhere, when schoolbased transmission occurred, the number of secondary cases was limited, ${ }^{23,31,46}$ although one large high school outbreak was described in Israel ${ }^{47}$ in the context of crowding and a concurrent heat wave. We observed a larger number of secondary cases when the index case was an adult, similar to the experience in England ${ }^{31}$ and Singapore. ${ }^{26}$ Our findings reinforce the observation that numerous cases in a school can reflect multiple introductions from the community rather than school-based transmissions. ${ }^{2}$

Of note, our study was conducted in the context of limited circulation of SARS-CoV-2 variants of concern, strong collaboration between the public health and education sectors, good school-based infection prevention and control measures, and rapid access to testing and contact tracing. Contact tracing within 24 hours and regular monitoring of cases and contacts may have prevented transmission to tertiary cases. Further studies will be required to evaluate the impact of individual infection prevention and control measures.

Caution should be taken in generalizing our results owing to differences in underlying epidemiology, public health measures, health system infrastructure and culture, among other factors that may differ by jurisdictions. However, our findings suggest that schools may be able to safely remain open in settings with moderate community transmission (i.e., weekly incidence of $10-100$ cases per 100000 as observed in this study) with infection prevention and control measures in place and sufficient public health capacity for rapid testing and contact tracing.

\begin{tabular}{|c|c|c|c|c|}
\hline \multirow[b]{2}{*}{ Characteristic } & \multicolumn{4}{|c|}{ No. $(\%)^{*}$} \\
\hline & $\begin{array}{c}\text { Grades } \mathrm{K}-7 \\
n=13 \text { clusters }\end{array}$ & $\begin{array}{l}\text { Grades } 8-12 \\
n=9 \text { clusters }\end{array}$ & $\begin{array}{c}\text { Staff only } \\
n=4 \text { clusters }\end{array}$ & $\begin{array}{c}\text { All grades } \\
n=26 \text { clusters }\end{array}$ \\
\hline $\begin{array}{l}\text { No. of cases per } \\
\text { cluster, median } \\
\text { (range) }\end{array}$ & $2(2-8)$ & $3(2-4)$ & $2.5(2-4)$ & $2.5(2-8)$ \\
\hline \multicolumn{5}{|c|}{ Role of index cases, $n=26$ cases } \\
\hline Staff & $7(53.8)$ & $3(33)$ & $4(100)$ & $14(54)$ \\
\hline Student & $6(46.2)$ & $6(67)$ & $0(0)$ & $12(46)$ \\
\hline \multicolumn{5}{|c|}{ Role of secondary cases, $n=55$ cases } \\
\hline Staff & $4(12.1)$ & $3(20.0)$ & $7(100)$ & $14(25.5)$ \\
\hline Student & $29(87.9)$ & $12(80.0)$ & $0(0)$ & $41(74.5)$ \\
\hline
\end{tabular}




\begin{tabular}{|c|c|c|c|c|}
\hline \multirow[b]{2}{*}{ Exposure setting } & \multicolumn{3}{|c|}{ No. of cases } & \multirow{2}{*}{$\begin{array}{c}\text { No. }(\%) \text { of cases } \\
\text { All grades } \\
n=59 \text { exposure } \\
\text { settings }\end{array}$} \\
\hline & $\begin{array}{l}\text { Grades } \mathrm{K}-7 \\
n=35 \text { exposure } \\
\text { settings }\end{array}$ & $\begin{array}{l}\text { Grades } 8-12 \\
n=17 \text { exposure } \\
\text { settings }\end{array}$ & $\begin{array}{l}\begin{array}{l}\text { Staff only } \\
n=7 \text { exposure } \\
\text { settings }\end{array}\end{array}$ & \\
\hline Class & $\begin{array}{c}28 \\
\text { (26 students, } 2 \text { staff) }\end{array}$ & $\begin{array}{c}11 \\
\text { (10 students, } 1 \text { staff) }\end{array}$ & $\begin{array}{c}2 \\
\text { (2 staff) }\end{array}$ & $41(69.5)$ \\
\hline $\begin{array}{l}\text { Office, meeting or staff } \\
\text { room }\end{array}$ & $\begin{array}{c}2 \\
\text { (2 staff) }\end{array}$ & $\begin{array}{c}1 \\
\text { (1 staff) }\end{array}$ & $\begin{array}{c}3 \\
\text { (3 staff) }\end{array}$ & $6(10.2)$ \\
\hline Socializing at school & $\begin{array}{c}3 \\
\text { (3 students) }\end{array}$ & $\begin{array}{c}2 \\
\text { (2 students) }\end{array}$ & 0 & $5(8.5)$ \\
\hline Unspecified interaction & 0 & $\begin{array}{c}1 \\
\text { (1 student) }\end{array}$ & $\begin{array}{c}2 \\
\text { (2 staff) }\end{array}$ & $3(5.1)$ \\
\hline Field trip & 0 & $\stackrel{2}{2}$ (1 student, 1 staff) & 0 & $2(3.4)$ \\
\hline Cohort† & $\begin{array}{c}2 \\
\text { (2 students) }\end{array}$ & 0 & 0 & $2(3.4)$ \\
\hline \multicolumn{5}{|c|}{$\begin{array}{l}\text { Note: } K=\text { kindergarten. } \\
\text { } \text { There were multiple potential exposure settings for some cases; an assessment of which within-school exposure setting was most likely } \\
\text { responsible for transmission was not included as part of this study. } \\
\text { †A cohort is a group of students and staff who remain together throughout a school term, the composition of which is consistent for all } \\
\text { activities that occur in schools. }\end{array}$} \\
\hline
\end{tabular}

\section{Limitations}

Our analysis was limited by reliance on routinely collected data and by potential recall bias owing to the self-reported nature of contact-tracing interview data, although case and proxy report was supplemented with information from school administrators as needed. Although medical health officers could request asymptomatic testing for the purposes of public health investigation, universal testing was not required. Transmissions to undetected (e.g., asymptomatic and not tested) secondary and tertiary cases were therefore not examined, which could disproportionately affect groups more likely to experience asymptomatic infection. However, studies that employed asymptomatic testing of school contacts reported low levels of transmission. ${ }^{24,25,28}$ Class sizes were not measured; thus, any association with school-based transmissions was not assessed.

Data extraction for the cluster analysis was not done in duplicate, except for cases with multiple exposures; the potential for misclassification of the likely source of acquisition for these cases was minimized via independent review by 2 members of the research team. This study was limited to descriptive statistics, and causal inferences cannot be drawn.

\section{Conclusion}

From Sept. 10 to Dec. 18, 2020, we detected minimal clusters and low rates of secondary transmission in schools; these findings relate primarily to symptomatic disease. There were no deaths, and severe disease was rare in our study population. In-person school attendance may not expose students and staff to higher risks than those experienced in the community when infection prevention and control measures are in place, and adequate case and contact management capacity is available. Acknowledging harms associated with decreased school attendance, policy-makers should focus on the implementation of measures to safely facilitate in-person learning, and consider school closures and widespread quarantine of students and staff with great caution.

\section{References}

1. Education: from disruption to recovery. Paris: UNESCO. Available: https:// en.unesco.org/covid19/educationresponse (accessed 2021 Jan. 21).

2. COVID-19 in children and the role of school settings in transmission: first update. Solna (Sweden): European Centre for Disease Prevention and Control; 2020.

3. Dove N, Wong J, Gustafson R, et al. Impact of school closures on learning, child and family well-being during the COVID-19 pandemic. Vancouver: BC Centre for Disease Control and BC Children's Hospital; 2020.

4. Xie X, Xue Q, Zhou Y, et al. Mental health status among children in home confinement during the coronavirus disease 2019 outbreak in Hubei Province, China. 7AMA Pediatr 2020;174:898-900.

5. COVID-19 survey. Vancouver: BC Centre for Disease Control. Available: http://www.bccdc.ca/health-info/diseases-conditions/covid-19/covid-19-survey (accessed 2021 Jan. 21).

6. Preliminary findings shared from COVID-19 child mental health research study. Toronto: SickKids; 2020; Available: https://www.sickkids.ca/en/news/ archive/2020/covid19-mental-health-study-findings/ (accessed 2021 Jan. 21).

7. Moore SA, Faulkner G, Rhodes RE, et al. Impact of the COVID-19 virus outbreak on movement and play behaviours of Canadian children and youth: a national survey. Int 7 Behav Nutr Phys Act 2020;17:85.

8. Averting a lost COVID generation: a six-point plan to respond, recover and reimagine a post-pandemic world for every child. New York: UNICEF; 2020.

9. Borkowski A, Correa JSO, Bundy DAP, et al. COVID-19: missing more than a classroom. The impact of school closures on children's nutrition. Innocenti Working Papers. Florence (Italy): UNICEF Office of Research - Innocenti.

10. Masonbrink AR, Hurley E. Advocating for children during the COVID-19 school closures. Pediatrics 2020;146:e20201440.

11. Patrick SW, Henkhaus LE, Zickafoose JS, et al. Well-being of parents and children during the COVID-19 pandemic: a national survey. Pediatrics 2020; 146:e2020016824

12. Kim LE, Asbury K. 'Like a rug had been pulled from under you': the impact of COVID-19 on teachers in England during the first six weeks of the UK lockdown. Br 7 Educ Psychol 2020;90:1062-83. 
13. Impacts of COVID-19 on Canadian families and children. Ottawa: Statistics Canada; 2020 July 9. Available: https://www150.statcan.gc.ca/n1/daily-quotidien /200709/dq200709a-eng.htm (accessed 2021 Jan. 21).

14. Hanushek EA, Woessmann L. The economic impacts of learning losses. Paris: OECD Publishing; 2020

15. Keogh-Brown MR, Jensen HT, Edmunds WJ, et al. The impact of Covid-19, associated behaviours and policies on the UK economy: a computable general equilibrium model. SSM Popul Health 2020;12:100651.

16. Bailey LC, Razzaghi H, Burrows EK, et al. Assessment of 135794 pediatric patients tested for severe acute respiratory syndrome coronavirus 2 across the United States. 7AMA Pediatr 2021;175:176-84.

17. Leeb RT, Price S, Sliwa S, et al. COVID-19 trends among school-aged children - United States, March 1-September 19, 2020. MMWR Morb Mortal Wkly Rep 2020;69:1410-5.

18. Ding Y, Yan H, Guo W. Clinical characteristics of children with COVID-19: a meta-analysis. Front Pediatr 2020;8:431.

19. Ludvigsson JF. Children are unlikely to be the main drivers of the COVID-19 pandemic: a systematic review. Acta Paediatr 2020;109:1525-30.

20. Dong Y, Mo X, Hu Y, et al. Epidemiology of COVID-19 among children in China. Pediatrics 2020;145:e20200702.

21. Götzinger F, Santiago-García B, Noguera-Julián A, et al. COVID-19 in children and adolescents in Europe: a multinational, multicentre cohort study. Lancet Child Adolesc Health 2020;4:653-61.

22. Liguoro I, Pilotto C, Bonanni M, et al. SARS-COV-2 infection in children and newborns: a systematic review. Eur 7 Pediatr 2020;179:1029-46.

23. Yoon Y, Kim KR, Park H, et al. Stepwise school opening and an impact on the epidemiology of COVID-19 in the children. 7 Korean Med Sci 2020;35:e414.

24. Brandal LT, Ofitserova TS, Meijerink H, et al. Minimal transmission of SARS-CoV-2 from paediatric COVID-19 cases in primary schools, Norway, August to November 2020. Euro Surveill 2021;26:2002011.

25. Macartney K, Quinn HE, Pillsbury AJ, et al. Transmission of SARS-CoV-2 in Australian educational settings: a prospective cohort study. Lancet Child Adolesc Health 2020;4:807-16.

26. Yung CF, Kam K-Q, Nadua KD, et al. Novel coronavirus 2019 transmission risk in educational settings. Clin Infect Dis 2021;72:1055-8.

27. Heavey L, Casey G, Kelly C, et al. No evidence of secondary transmission of COVID-19 from children attending school in Ireland, 2020. Euro Surveill 2020;25:2000903.

28. Larosa E, Djuric O, Cassinadri M, et al. Secondary transmission of COVID19 in preschool and school settings in northern Italy after their reopening in September 2020: a population-based study. Euro Surveill 2020;25:2001911.

29. Zimmerman KO, Akinboyo IC, Brookhart MA, et al. Incidence and secondary transmission of SARS-CoV-2 infections in schools. Pediatrics 2021;147: e2020048090.

30. Mossong J, Mombaerts L, Veiber L, et al. SARS-CoV-2 transmission in educational settings during an early summer epidemic wave in Luxembourg, 2020. BMC Infect Dis 2021;21:417.

31. Ismail SA, Saliba V, Bernal JL, et al. SARS-CoV-2 infection and transmission in educational settings: a prospective, cross-sectional analysis of infection clusters and outbreaks in England. Lancet Infect Dis 2021;21:344-53.

32. Ehrhardt J, Ekinci A, Krehl H, et al. Transmission of SARS-CoV-2 in children aged 0 to 19 years in childcare facilities and schools after their reopening in May 2020, Baden-Württemberg, Germany. Euro Surveill 2020;25:2001587.

33. Falk A, Benda A, Falk P, et al. COVID-19 cases and transmission in $17 \mathrm{~K}-12$ schools - Wood County, Wisconsin, August 31-November 29, 2020. MMWR Morb Mortal Wkly Rep 2021;70:136-40.

34. Danis K, Epaulard O, Bénet T, et al. Cluster of coronavirus disease 2019 (COVID-19) in the French Alps, February 2020. Clin Infect Dis 2020;71:825-32.

35. Somekh I, Shohat T, Boker LK, et al. Reopening schools and the dynamics of SARS-CoV-2 infections in Israel: a nationwide study. Clin Infect Dis 2021 Jan. 18 [Epub ahead of print]. doi: 10.1093/cid/ciab035.

36. Covid-19 in schoolchildren: a comparison between Finland and Sweden. Solna (Sweden): Public Health Agency of Sweden; 2020.

37. Living Rapid Review Update 11: What is the specific role of daycares and schools in COVID-19 transmission? Hamilton (ON): National Collaborating Centre for Methods and Tools; 2021.

38. Special Focus: COVID-19 in schools. Ottawa: Ottawa Public Health; 2021. Available: https://www.ottawapublichealth.ca/en/reports-research-and-statistics/ resources/Documents/SpecialReport_COVIDinSchools_EN_final_2021-02-01. pdf (accessed 2021 Apr. 16).
39. British Columbia: population estimates. Government of British Columbia. Available: https://bcstats.shinyapps.io/popApp/ (accessed 2021 Jan. 21).

40. COVID-19 (novel coronavirus): orders and notices. Victoria: British Columbia Ministry of Health. Available: https://www2.gov.bc.ca/gov/content/health/about -bc-s-health-care-system/office-of-the-provincial-health-officer/current-health -topics/covid-19-novel-coronavirus\#archived-orders (accessed 2021 Apr. 16).

41. Phases of COVID-19 testing in BC. Vancouver: BC Centre for Disease Control; updated 2020 June 16. Available: www.bccdc.ca/health-info/diseases-conditions/ covid-19/testing/phases-of-covid-19-testing-in-bc (accessed 2021 Apr. 16).

42. COVID-19 public health guidance for K-12 schools. Vancouver: BC Centre for Disease Control; updated 2021 Feb. 4.

43. Interim guidance: Public bealth management of cases and contacts associated with novel coronavirus (COVID-19) in the community. Vancouver: BC Centre for Disease Control; 2021.

44. COVID-19 case report form. Vancouver: BC Centre for Disease Control.

45. BCCDC COVID-19 epidemiology app. Vancouver: BC Centre for Disease Control; 2021. Available: https://bccdc.shinyapps.io/covid19_global_epi_app/ (accessed 2021 June 11)

46. Fong MW, Cowling BJ, Leung GM, et al. Letter to the editor: COVID-19 cases among school-aged children and school-based measures in Hong Kong, July 2020. Euro Surveill 2020;25:2001671.

47. Stein-Zamir C, Abramson N, Shoob H, et al. A large COVID-19 outbreak in a high school 10 days after schools' reopening, Israel, May 2020. Euro Surveill 2020;25:2001352.

Affiliations: School of Population and Public Health (Bark, McKee), University of British Columbia; Population Health Surveillance Unit (Dhillon, St-Jean, Kinniburgh), Vancouver Coastal Health; Population and Public Health (McKee), BC Centre for Disease Control; Office of the Chief Medical Health Officer (Choi), Vancouver Coastal Health, Vancouver, BC

Contributors: Alexandra Choi and Geoff McKee conceived of the study, and all authors contributed to the design. All authors contributed to the acquisition and preparation of data. Nalin Dhillon, Diana Bark and Alexandra Choi contributed to the analysis of data. Nalin Dhillon, Diana Bark, Alexandra Choi and Geoff McKee wrote the paper, with input from all authors. All authors gave final approval of the version to be published and agreed to be accountable for all aspects of the work.

Funding: Neither the study authors nor their institutions received payment or services at any time from any third parties for any aspects of the submitted work.

Content licence: This is an Open Access article distributed in accordance with the terms of the Creative Commons Attribution (CC BY-NC-ND 4.0) licence, which permits use, distribution and reproduction in any medium, provided that the original publication is properly cited, the use is noncommercial (i.e., research or educational use), and no modifications or adaptations are made. See: https://creativecommons.org/licenses/ by-nc-nd/4.0/

Data sharing: The study data are not available for use by other researchers, other than that which are presented in the manuscript.

Acknowledgements: The authors thank Amina Moustaqim-Barrette MPH (Vancouver Coastal Health) and Moe Zandy MSc (British Columbia Centre for Disease Control) for their contributions to data compilation and visualization.

Disclaimer: The views expressed in the article are the authors' own and not an official position of Vancouver Coastal Health or the BC Centre for Disease Control.

Supplemental information: For reviewer comments and the original submission of this manuscript, please see www.cmajopen.ca/content/9/3/ E810/suppl/DC1. 